- creating social workers

- developing psychiatric departments in general hospitals

- integrating mental health service users and civil organisations in political decision-making.

And last but not least, emphasis should be put on the urgent need to develop community care and to establish rehabilitation programmes.

\section{References}

Bégué, J. M. (1996) French psychiatry in Algeria (1830-1962): from colonial to transcultural. History of Psychiatry, 7, 533-548.

Bensmail, B. (1993) Suicide et conduits suicidaires en milieu maghrébin. In La psychiatrie aujourd'hui (ed. B. Bensmail), p. 260. Office des Publications Universitaire.

Kacha, F. (2005) La psychiatrie en Algérie. L'Information Psychiatrique, 81, 145-148.
Kacha, F. (2010) La santé mentale en Algérie. Journée Parlementaire sur la Santé, 55-62. Available at http://www. majliselouma.dz/textes/autresdoc/JP\% 20sur \% 20la \% 20Sante2.pdf (accessed 26 January 2014).

Office National des Statistiques (2013) Data from http://www.ons. dz (accessed January 2014).

United Nations (2012) Statistical Annex. Available at http:// www.un.org/en/development/desa/policy/wesp/wesp_ current/2012country class.pdf (accessed July 2014).

World Bank (2013) Data from http://data.worldbank.org/country/ algeria (accessed 23 December 2014).

World Health Organization (2011) Mental Health Atlas. Available at http://www.who.int/mental_health/evidence/atlas/profiles/ dza_mh_profile.pdf (accessed December 2013).

World Health Organization (2014) Data from http://apps.who.int/ gho/data/node.country.country-DZA (accessed 21 December 2014).

Zahir, A. (2012) A l'issue du 1er congrès national de santé mentale, Ould Abbes annonce: dix huit projets de création de nouveaux établissements hospitaliers. Available at http://www.lactualite-dz. info (accessed 3 July 2014).
MENTAL HEALTHLAW PROFILE

\title{
Mental health legislation in Algeria
}

\author{
Zoubir Benmebarek
}

EHS Psychiatrique El Madher, Batna, Algeria, email zoubirbenmeb@gmail.com

\begin{abstract}
Mental health law in Algeria originates from the French colonial era. Although several pieces of legislation deal with mental disorders, their implementation remains unsatisfactory and does not meet the real needs of healthcare providers. Amendment of the current mental health law is required to enhance the delivery of care but also to protect those with a mental disorder from abuse.
\end{abstract}

Algeria is the largest country in Africa, with an area of $2382000 \mathrm{~km}^{2}$. The population is 37.9 million (Office National des Statistiques, 2013). The country is in the upper middle income group (United Nations, 2012). In Algeria, neuropsychiatric disorders are estimated to contribute $13.1 \%$ of the global burden of disease (World Health Organization, 2011). Further details of mental healthcare in the country are provided in the accompanying Country Profile on Algeria in this issue (pp. 10-12).

\section{Historical background}

Before the French army invaded Algeria in 1830, people with a mental illness, especially those presenting a risk to themselves or to others, were housed in the maristans (medical institutions) inherited from the Ottoman period. The care of patients with no behavioural disturbances was provided mainly by their families (Bégué, 1996).

In the early colonial era, patients were transferred to asylums in southern France. This persisted for more than a century despite the enactment in 1878 of a decree which extended the application of a French mental health law of 30 June 1838 to Algeria, the enforcement of which was hampered by a lack of hospitals.

Colonial psychiatry was founded by the 1912 Tunis congress of French alienists but the implementation of its recommendations began only in the 1930s (Bégué, 1996). At independence, in 1962, Algeria had about 6000 psychiatric beds and a network of hospitals and out-patient facilities (Kacha, 2005).

\section{After independence}

The French mental health law regulated psychiatric institutions till 1975 and the first Algerian mental health law was promulgated in 1976 (Decree 76-79 of 23 October 1976); it was based on the previous French law (Bakiri, 1993).

The second mental health law was introduced in 1985, in the form of the third chapter of the public health law (Law 85-05 of 16 February 1985). Modifications concerned the form rather than the content of the previous law (Bakiri, 1993). It is the legislation that applies today.

\section{Law 85-05}

Law 85-05 has four parts.

\section{Part 1}

This part covers the types of hospitalisation in psychiatric units. In some regards it is imprecise and even contradictory in its formulations. For 
instance, patients themselves can apply for involuntary admission; furthermore, admission by a third party is considered to be voluntary hospitalisation in one section of the legislation (psychiatric observation on an open unit) and to be involuntary in the following section (voluntary placement on a closed ward).

There are two kinds of voluntary admission:

- free admission with a patient's consent

- admission for psychiatric observation, decided at the verbal request of the patient, a family member or a local authority (governor, mayor or police officer).

There are also two types of involuntary admission:

- Admission by a third party, which will be effective upon a written request by a patient's relative or a legal guardian. The patient is hospitalised and discharged according to the physician's decision, or at the patient's or relative's request.

- An order for involuntary admission, which may be made by a local governor, the wali (a civil government representative), based on a medical certificate stating that the patient presents an imminent risk to him- or herself or to others on account of a psychiatric disorder and refuses or is unable to give informed consent for voluntary admission. This entails admission to a closed hospital ward and lasts a maximum of 6 months, but is renewable. Discharge can take place before the maximum term, on the recommendation of a physician: the physician informs the wali, through a medical report, about the psychiatric state of the patient, who is discharged unless the wali rejects the physician's decision.

Where the latter type of involuntary admission is disputed, a commission (presided over by a judge and assisted by a wali's representative and two psychiatrists) is set up to examine the case and make a final decision. According to the law, such a dispute arises:

- either when the wali considers, after an expert opinion, that the request for involuntary hospitalisation made by the psychiatrist is unjustified

- or when the wali rejects a physician's decision to discharge the patient before the end of the term of involuntary treatment, in which case both the psychiatrist and the wali can separately address the commission to settle the outcome.

The commission has to reach a decision within 2 months and after evidence from two psychiatric experts. But the text of Law 85-05 is ambiguous here, since, in this case, a previous article of the law stipulates that when the wali rejects the physician's decision the duration of involuntary treatment is prolonged automatically to the maximum term; therefore, the wali does not need to address the commission.
A patient's relative can also appeal to the commission against any coercive measure.

Another form of involuntary procedure is the compulsory psychiatric examination, which can be ordered by the district attorney or the wali following presentation of a medical certificate stating the person is presenting an imminent risk to him- or herself or to others, on account of a psychiatric disorder. If the psychiatric examination confirms that there is such a risk due to a psychiatric disorder, the patient will be involuntarily hospitalised.

\section{Part 2}

This section further controls involuntary admission. The hospital should inform the wali and the district attorney of all cases of involuntary admission. These authorities have to visit the local closed wards at least twice every year to enquire about patients.

Young patients (under 16 years) and old persons with cognitive impairment are excluded from all coercive measures but the law does not provide alternatives for them.

\section{Part 3}

Part 3 deals with involuntary out-patient treatment for those who, due to a mental disorder, present a risk to themselves or to others if they do not comply with treatment. Following the presentation of a medical certificate, the wali issues a decree to assign the patient to regular treatment and surveillance in an out-patient facility; the duration of the order is 6 months, but it is renewable. No further details are stipulated by the law regarding the care that is to be provided. In fact, in practice this measure has never been used, mainly due to shortages of professional staff and psychiatric facilities.

\section{Part 4}

This section simply states that all measures relating to involuntary procedures are subject to appeal.

\section{Mental health plan}

A national programme of mental health was formulated in 2001 and revised in 2009 (World Health Organization, 2011). It aims to reduce the prevalence of mental disturbances, and to implement less expensive, better adapted and more efficient mental healthcare services. It also calls for new legislation to be implemented (Santé Algérie, 2001).

The programme made very slow progress and most of its objectives have not yet been met. A revision of the mental health law was scheduled for 2002 but has not yet been done, and out-patient facilities were planned to cover the whole of the country but this has not been achieved. Nonetheless, training in child psychiatry was planned in 2002 and began in 2006.

\section{Policy on substance misuse}

Tackling the problem of substance misuse began in the early 1990s. In 1997 the National Office on Drug Misuse was created by the Ministry of Justice 
and became effective in 2002. Among the objectives of the Office are the following:

- to set a national strategy to prevent drug misuse

- to coordinate different services dealing with substance misuse

- to fight drug smuggling.

A national policy on drug misuse was adopted in 2003 by the government (Sayeh, 2007). In 2004 a law on the prevention of substance misuse and the trafficking of illicit drugs and psychotropic substances was promulgated. While it is largely repressive, it does provide for substance misusers to undergo compulsory treatment under a court order instead of imprisonment.

\section{Forensic psychiatry}

Article 47 of the Penal Code states that a person who was mentally disordered at the time of committing an offence is not punishable, but it is up to the judge to decide whether the offender should be sentenced to a jail term or committed to a psychiatric high-security unit, as stipulated by article 21 of the Penal Code. The latter is the more frequent outcome. In these high-security units, only mental health staff provide surveillance.

Article 22 of the Penal Code states that if an offence is linked to substance misuse, the judge can order compulsory hospitalisation in a highsecurity unit.

Usually the judge mandates an expert to examine the patient, who then states whether the accused is or is not responsible for the offence. In the case of mental disorder, a trial is not held and the patient is sent to a high-security hospital. Forensic psychiatrists are not usually called upon to testify in court as expert witnesses, as a written report is sufficient.

There are no psychiatric services in prisons, but under an agreement between the Ministry of Health and the Ministry of Justice regular consultations by public health psychiatrists are provided for prisoners in need.

\section{Mental health in civil law}

The Family Code, issued in 1984, provides a legal framework for mental capacity and guardianship. 'Interdiction' (total deprivation of legal capacity and the institution of full guardianship) is the only measure for the protection and representation of incapacitated persons under the Code; that is, there is no other measure for persons with partial capacity.

In any civil case - for example involving divorce or child custody - when a mental disorder is suspected the judge can order a psychiatric examination of mental capacity. Expert opinion is highly esteemed and will have a prominent role in the judge's ruling.

\section{Discussion}

Since its enactment, the mental health law (Law 85-05) has received a lot of criticism, especially in relation to its inadequacy and the fact that it rarely seems to have been applied correctly. Bakiri (2008), for instance, criticised it for the confusion, imprecision and even contradiction in its wording, especially in relation to the kinds of hospitalisation it specifies, as noted above.

Furthermore, the ministerial enactments required for the implementation of some parts of the law have never been issued, for example for those governing how to appeal against the use of coercive measures, or which experts can be referred to by the wali to refuse an application for involuntary admission in litigation cases (Kacha 2005).

The law is in line with a sociocultural perception of mental illness in which social protection prevails over individual freedom (physicians and relatives are given the power to make decisions on behalf of the patient; in case of involuntary admission the patient is not given a right to appeal to a commission). Thus, the classical model of care is applied, with psychiatric hospital as the backbone of care delivery.

In practice, however, psychiatric settings are working essentially outside the scope of the law (Kacha, 2005). For instance, patients are often hospitalised upon a joint decision between the family and the physician, through verbal agreement. The opinion of the patient is not a matter of importance since the mental disorder justifies hospitalisation. This is then considered to be voluntary hospitalisation in all the official statistics. Consequently, all psychiatric hospitals are effectively closed wards and it is well established, at least socially, that the need for care outweighs individual freedom.

Currently there is no way to appeal against involuntary admission but the huge pressure on psychiatric services and the shortage of beds does not allow the overuse of coercive measures or other forms of abuse.

There are no psychiatric guidelines or legal provisions for the use of electroconvulsive therapy, physical restraint or seclusion. No informed consent is needed for treatment and the physician is free to choose any treatment considered beneficial for the patient.

There is no compulsory out-patient care and a law on addiction is yet to be implemented, due to a shortage of specialist units.

The family remains the main carers for people who are mentally ill, even in the most serious cases. They bear the heaviest burden, and this is encouraged by a humanitarian tolerance of mental illness that characterises Algerian society.

\section{Conclusion}

A third mental health law is in the process of being drafted, but in the meantime the first two have not been implemented or evaluated adequately. This has not, though, hampered the provision of care in hospitals or in out-patient facilities. To make up for shortcomings of the previous laws, the drafting of the forthcoming mental health act should be done in consultation with professionals and civil 
organisations. It should be clear and practical in its formulations, especially those pertaining to involuntary hospitalisation. It should take into account the availability of in-patient and outpatient facilities and fit with existing resources to facilitate its acceptance and implementation. The rights of hospitalised patients should be reviewed to better protect them from abuse. Voluntary admission should be encouraged and the length of involuntary hospitalisation shortened. Review by judicial authorities of compulsory orders should be done earlier and more frequently, and patients themselves should have the right to appeal against the imposition of involuntary measures.

For the time being and in the short term at least, the country has enough resources (human and financial) to move towards a modern, humane and respectful mental healthcare system.

\section{References}

Bakiri, A. (1993) Au secours, I'asile revient. In La psychiatrie aujourd'hui (ed. B. Bensmail), p. 260. Office des Publications Universitaires.
Bakiri, A. (2008) La législation psychiatrique algérienne. Historique et actualités. Le Lien Psy, 1, 61-62.

Bégué, J. M. (1996) French psychiatry in Algeria (1830-1962): from colonial to transcultural. History of Psychiatry, 7, 533-548.

Kacha, F. (2005) La psychiatrie en Algérie. L'Information Psychiatrique, 81, 145-148.

Office National des Statistiques (2013) Data from http://www. ons.dz (accessed January 2014).

Santé Algérie (2001) La santé mentale en Algérie. Available at http://www.sante.dz/Dossiers/dass/sante-mentale3.htm (accessed January 2014).

Sayeh, A. (2007) La politique nationale de lutte contre la drogue et la toxicomanie. Available at http://www.onlcdt.mjustice.dz/ onlcdt_fr/fichiers_communications/communications[18].pdf accessed January 2014).

United Nations (2012) Statistical Annex. Available at http:// www.un.org/en/development/desa/policy/wesp/wesp_ current/2012country_class.pdf (accessed July 2014).

World Health Organization (2011) Mental Health Atlas. Available at http://www.who.int/mental_health/evidence/atlas/profiles/ dza_mh_profile.pdf (accessed December 2013).

\section{SPECIAL} PAPER

\title{
The impact factor and psychiatry journals: an international perspective
}

\author{
Sundararajan Rajagopal
}

Consultant Psychiatrist, Chennai, India, email rajagsr@hotmail. com
The impact factor (IF) is a metric for assessing academic journals. Despite its shortcomings, the IF is the preeminent yardstick by which the quality of scientific journals is determined. In this paper, the key aspects of the IF are covered from an international perspective, with a specific emphasis on psychiatry journals.

The concept of the impact factor (IF) was introduced by Eugene Garfield, an American linguist, in 1955 (Garfield, 1955). It was originally suggested as a measure that could help librarians decide which journals they should subscribe to. Over the years, its importance has grown exponentially, to the point that the IF is today, by far, the foremost criterion by which a scientific journal's standing is evaluated. Furthermore, the IF can significantly boost the subscription and advertising revenues of a journal.

In addition, for researchers, getting papers published in high-IF journals can considerably enhance career progression and increase the likelihood of research grants being awarded. The maxim 'publish or perish' is well known in academic circles, and that applies particularly to publishing in high-IF journals.

\section{Definition of IF}

The IF of a journal is calculated each year. The IF of journal $\mathrm{J}$ for year $\mathrm{Y}$ is the number of citations in year $\mathrm{Y}$ of all articles published in journal $\mathrm{J}$ in years Y-1 and Y-2 (i.e. the two preceding years), divided by the total number of articles in journal $\mathrm{J}$ in years $\mathrm{Y}-1$ and $\mathrm{Y}-2$.

For example, say that journal J published 100 articles in 2010 and 100 articles in 2011, and that these articles were cited 450 times in other articles in various journals (including journal J) in 2012. The IF of journal $\mathrm{J}$ for the year 2012 will be 450 divided by $200(100+100)$, which is 2.25 .

The IF is calculated based on the Journal Citation Reports (JCR) published by Clarivate Analytics (integrated with its Web of Science product, previously owned by Thomson Reuters and formerly known as ISI Web of Knowledge).

\section{General medicine journals and psychiatry journals with the highest IFs}

The five general medicine journals with the highest IFs in 2014 were:

- New England Journal of Medicine, $\mathrm{IF}=55.8$

- Lancet, $\mathrm{IF}=45.2$

- $J A M A, \mathrm{IF}=35.3$ 